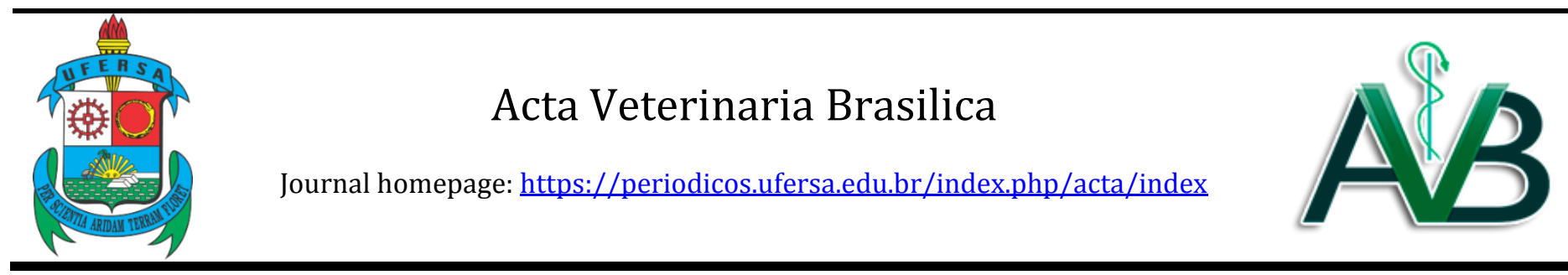

Original Article

\title{
Community perception and attitudes about the behavior of stray dogs in a college campus
}

\author{
Edilberto Martinez ${ }^{1}$, Clarice Silva Cesárioº ${ }^{2}$ João Vítor Dias³ ${ }^{3}$ Ita de Oliveira e Silva ${ }^{4}$, Vanner Boere Souza ${ }^{4 *}$ \\ ${ }^{1}$ Programa de Pós-graduação em Psicologia Social, Departamento de Psicologia Social e Institucional, Universidade do Estado do Rio de \\ Janeiro, Rio de Janeiro, RJ, Brazil. Departamento de Psicologia Social e Institucional, Universidade do Estado do Rio de Janeiro, Rio de \\ Janeiro, RJ, Brazil. \\ 2 Programa de Pós-graduação em Biologia Animal, Instituto de Ciências Biológicas e da Saúde, Universidade Federal de Viçosa, MG, \\ Brazil. \\ 3Departamento de Zootecnia da Universidade Federal de Viçosa, Viçosa, MG, Brazil. \\ ${ }^{4}$ Instituto de Humanidades, Artes e Ciências, Campus Jorge Amado, Universidade Federal do Sul da Bahia, Itabuna, BA, Brazil.
}

\section{A R T I C L E I N F O}

\begin{tabular}{l} 
Article history \\
Received 21 May 2017 \\
Received in revised form 29 August 2017 \\
Accepted 14 September 2017 \\
\hline Keywords: \\
Anthrozoology \\
Dogs \\
Canis lupus familiaris \\
UFV
\end{tabular}

\section{A B S T R A C T}

\begin{abstract}
Stray dogs are part of the scene in many cities, including Viçosa, where they gather at UFV campus. In order to understand the relation people have with stray dogs, 385 individuals answered to a semi-structured questionnaire. The number of stray dogs is high for most people; this dog population is mostly composed of adult males of undefined breed. Dogs perform most of their activities in the campus. Food sources appear to be varying and lure dogs into central territories, thus reducing the predatory pressure on wildlife. Interviewees are concerned with the low well-being level faced by stray dogs, although just half of them would adopt a dog to minimize the problem; most interviewees are against euthanasia. People acknowledge that stray dogs in the campus are an issue to the community and to dogs themselves. It seems that people are willing to find solutions to the stray dog issue.
\end{abstract}

\section{INTRODUCTION}

Dogs (Canis lupus familiaris) who do not belong to somebody's real state or assets, or who do not have a tutor, belong to a category overall called "stray dogs" (SERPELL, 1995). Stray dogs do not have a defined tutor and do not live in restrict areas. They are on the streets because they were abandoned or, more rarely, because they were generated by bitches who do not have exclusive-dependence relation to a person, or group of people; thus, they are not linked to a specific territory. Stray dogs are tolerated in some societies, since they are considered to be domesticated, relatively sociable and inserted in the urban context, although control measures are part of the public health policies in Western countries (SERPELL, 1995). The stray dog population is increasing in many countries such as Canada, Italy and in countries from the old Czechoslovakia, despite the control efforts (MATTER; DANIELS, 2000; VOSLÁRVÁ; PASSANTINO, 2012). With regard to Brazil, despite the excellency in controlling and preventing rabies either in humans, wild animals, herbivores, felines or canines, there is no official statistics about the number of dogs living in the streets of the country (BRASIL, 2011).

Stray dogs live with low quality of life, with little or zero long-term association with people and, in most of the cases, they are subjected to social restrictions, starvation, extreme weather events, and run the risk of been knocked down by vehicles in the traffic jam and of being exposed to pathological agents (BOITANI et al., 1995). Dogs are involved in rabies, leishmaniasis,

*Corresponding author: vannerboere@uol.com.br 
echinococcosis, foot-and-mouth disease (tungiasis) and geographic worm disease epidemiological chains, as well as with the cutaneous larva migrans (TAN, 1997).

Another aspect, which is little addressed, is the impact stray dogs have on the urban fauna or on areas under environmental protection (MARTINEZ et al., 2013; FRIGERI; CASSANO; PARDINI, 2014). The knowledge about disease transmission is limited to rabies, although parvovirus, distemper and other infectious diseases have high transmissibility among dogs and wild species. There are few epidemiological studies about the impact dogs have on the wild fauna (DASZAK; CUNNINGHAM; HYATT, 2000; CAMPOS et al., 2007; MARTINEZ et al., 2013; FRIGERI; CASSANO; PARDINI, 2014).

One of the locations in Viçosa presenting the highest occurrence of stray dogs is the central campus Universidade Federal de Viçosa (UFV), where this population gathers freely on a daily basis. The resources to control this population are limited in comparison to the apparent speed the number of these dogs seem to increase in the campus.

The scientific literature counts on scarce studies on people's perception about stray dogs, fact that is actually surprising, since such studies are necessary in order to draw control strategies (FRANK, 2004; WHO, 1990). The lack of precise information concerning the community perception about stray dogs may limit initiatives and actions to deal with the problem.

The present study describes the investigation about how the community, and UFV visitors, understand the life of stray dogs in the campus, and what are their position concerning the conduction of control policies.

\section{MATERIALS AND METHODS}

The study was conducted at Campus da Universidade Federal de Viçosa $\left(20^{\circ} 35^{\prime}\right.$ to $28^{\circ} 50^{\prime} \mathrm{S}$, and $42^{\circ} 45^{\prime}$ to $43^{\circ} 00^{\prime} \mathrm{W}$ ), Viçosa, Minas Gerais, Brazil. The campus area covers 1601.01 ha, besides having spots of montane semi-deciduous forests (PEREIRA et al., 2001) and of experimental plantations. The area inside the campus where people participating in the present sample were approached held $0.4 \mathrm{Km}^{2}$ around the main pathways in the campus. A population of approximately 20,000 people among professors, technicians and students (PAULA et al., 2004; EISENLOHR et al., 2008; IBGE, 2010 ), besides the fluctuating populations in the region, transit freely in this site.

The structured questionnaire held 30 questions about the interviewees, their perception about and solutions to the stray dog issue in the campus. Only people who have been visiting the campus for at least one year were interviewed. Two methods were adopted to collect data; questionnaires were applied through direct contact, or through electronic means (Internet). Both interviews, personal and on the internet, which were conducted for 15 days in May 2012, held the same questions and options of answer.

The project was approved by the Ethics Commission for Animal Use (Comissão de Ética para Uso de Animais CEUA) / UFV process n. 25 / 2011). There was no submission standard in place to the Ethics Committee on Human Research at the time to put the project in practice and to apply the questionnaires. No loss or discomfort were recorded by the interviewees. Data were analyzed through descriptive statistics; moreover, a similarity test between variables (Spearman correlation), aiming at getting to know any difference between results of the data collection methods, was applied at $r>0.5$ as similarity criterion. The Chi-square test was used to identify some statistic differences between questions and the answers given in the personal and internet interviews. The area of $0.4 \mathrm{Km}^{2}$ was taken into account to calculate the demographic density of stray dogs in the campus reported by the interviewees.

\section{RESULTS}

The total of 385 questionnaires were answered, 165 through personal interview and 220 on the internet. Five people refused to answer the questionnaire in the personal interview; 20 questionnaires were refused on the internet. The proximity matrix for each answer referring to the same question in both data collection methods showed that answers to all questions were highly associated, the similarity sum between answers to the same questions recorded 95\% ( $\Sigma r=0.95)$, although there was maximum and minimum similarity variation in the same questions from $100 \%$ to $56 \%$, respectively. However, the Chi-square test evidenced statistical difference $(\mathrm{p}<0.05)$ in answers to just one question, which is described as follows: "Have you witnessed them (stray dogs in the campus) being fed by other people". Both interviewee types used the campus in an equivalent way; personal interviewees highlighted this feeding phenomenon more often than the internet interviewees. The explanation to this difference may be related to lack of memory inhibition in a more reserved environment, although such assumption would demand deeper analyses in order to be confirmed.

Women represented $54.0 \%$ and men, $46.6 \%$, of the total of interviewees. Of the total of individuals participating in the research, $73.0 \%$ were students, $9.1 \%$ were professors, $11.4 \%$ were technicians at UFV and $6 \%$ were passers-by. Interviewees were used to the campus routine, since $89.4 \%$ of them used to go to the campus five times a week, or more. The other interviewees $(10.6 \%)$ used to go to the campus two to four times a week. 
According to $35.8 \%$ of the interviewees, there are more male dogs in the campus, although $5.2 \%$ of them consider that the proportion of females is higher. The perception that there is a balance between the number of males and bitches was reported by $22.1 \%$ of interviewees. The others (36.9\%) could not state the sex prevailing in the campus. Most of the interviewees $(79.5 \%)$ considered that the dogs were adult, although a small portion of them (6.0\%) thought the dogs were old; whereas another portion, even smaller (0.5\%), stated that these dogs were puppies; $14 \%$ of the interviewees could not identify the prevailing aging group of the animals.

Part of the participants (59.2\%) stated that they see 10 dogs per day in the campus, on average; other $32.2 \%$ use to see from 10 to 20 , and $5.7 \%$ often see more than 20 dogs per day. Only $2.9 \%$ of the interviewees did not know the amount of dogs daily seen by them.

Most of the interviewees (94.3\%) stated that almost all dogs had no defined breed (NDB), whereas $0.3 \%$ stated that all dogs were NDB. The rest of them (5.4\%) stated that there were more breed dogs than NDB ones.

Among interviewees, $43.6 \%$ mentioned to observe bitches in heat up to three times per semester, and $38.2 \%$ reported the occurrence of it every month. Only $12.5 \%$ of the interviewees observed bitches in heat once a year, whereas the smallest number of them had never observed (4.4\%) bitches in heat, or could not answer $(1.3 \%)$. When bitches in heat were addressed, $41.8 \%$ of interviewees reported the presence of five males, or more, around the female. Part of the interviewees $(43.1 \%)$ stated to have seen bitches in heat with two to four males around them, and only $0.5 \%$ states to have observed only one male close by. A small percentage $(14.5 \%)$ did not know how to answer this question.

It is rare to have interviewees witnessing females with puppies. More than half (50.6\%) of the interviewees stated to have never seen it, and $36.6 \%$ reported to have witnessed females with puppies just once. Only 10.4\% reported to have seen it from two to six times a year. The other interviewees could not state.

The same dogs were seen every month by $48.6 \%$ of the interviewees, but $28.6 \%$ of them reported seeing the same dog once to three times per semester. The other interviewees stated to rarely see the same dog more than once in the campus. According to $66.0 \%$ of the interviewees, stray dogs permanently occupy the college campus. A small fraction of interviewees (0.8\%) stated that none of the dogs lives in the campus. The total of $15.1 \%$ of interviewees stated that only half of the dogs live in the area, whereas $5.7 \%$ believed that this number accounts for less than half. A small fraction of interviewees (12.5\%) did not know how to answer.
According to $76.1 \%$ of the interviewees, dogs are more often seen close to cafeterias and snack shops. The other interviewees reported that dogs often stay on buildings entrances. Most of the interviewees (39.7\%) could not inform if the dogs also visited other areas in town, but $9.6 \%$ emphasized that the dogs were never seen outside the campus. The same percentage of interviewees, 9.6\%, stated that dogs were rarely seen beyond the college campus walls, on the city streets, whereas $32.1 \%$ of them reported that dogs were rarely seen outside the campus perimeter.

Most of the interviewees (90.1\%) have never witnessed abandonment, and it goes against the $9.9 \%$ who have witnessed such practice. Interviewees did not know somebody who have abandoned dogs (82.3\%); however, $17.7 \%$ of them knew a person who have abandoned a dog; in one case $(0.4 \%)$, the interviewee stated to have abandoned a dog in the campus him/herself.

Less than half of the interviewees (41.2\%) stated to have fed the dogs, but only $7.5 \%$ do it on a regular basis (at least once a week). Most of the interviewees (91.9\%) stated to have witnessed somebody providing food to the dogs in the campus, whereas $8.1 \%$ deny to have observed such phenomenon. There was statistical difference in this item between questionnaire application methods. Personal interviewees more often stated to have seen these situations; therefore, the presence in the campus at the time of the interview could have been influenced by the time coincidence concerning dogs on sight being fed by others. According to $84.4 \%$ of the interviewees, garbage can also be explored by stray dogs. A small fraction (15.6\%) of the interviewees have never observed a garbage being explored by a dog looking for food. The predatory impact on the wild fauna is one of the problems that can be minimized through stray dog control (LENTH; KNIGHT; BRENNAN, 2008). Most of the interviewees (60.2\%) stated to have seen dogs in the campus woods, but only $9.6 \%$ stated to have seen it often. On the other hand, $22.3 \%$ of the interviewees stated never to have seen dogs in the woods.

Stray dogs may attack or chase small, medium and bigsized animals (MARTINEZ et al., 2013). Most of the interviewees $(81.0 \%)$ have never seen a dog chasing or attacking a small animal, except for birds. Bigger-sized animals are more often seen under the attack of dogs, according to $33.5 \%$ of the interviewees, and it goes against the $66.5 \%$ of interviewees who denied to have seen an attack.

Dogs have never attacked or chased birds according to $73.5 \%$ of the interviewees, but $26.5 \%$ disagree with such statement. Butchery habits were never observed by $94.8 \%$ of the interviewees. The rest of the interviewees $(5.2 \%)$ stated to rarely see dogs feeding on the carcasses of decaying animals. 
Most of the interviewees (79.0\%) believed that animals running free in the campus are a problem to society and to the well-being of the dogs themselves, in contrast to the $15.8 \%$ of those who do not see these dogs as an issue. Interviewees did not state whether the dogs are an issue or not, in $5.2 \%$ of the cases.

Graphic 1 - Interviewees opinion about the euthanasia of dogs as the solution to the stray dog issue.

\section{EUTHANASIA}

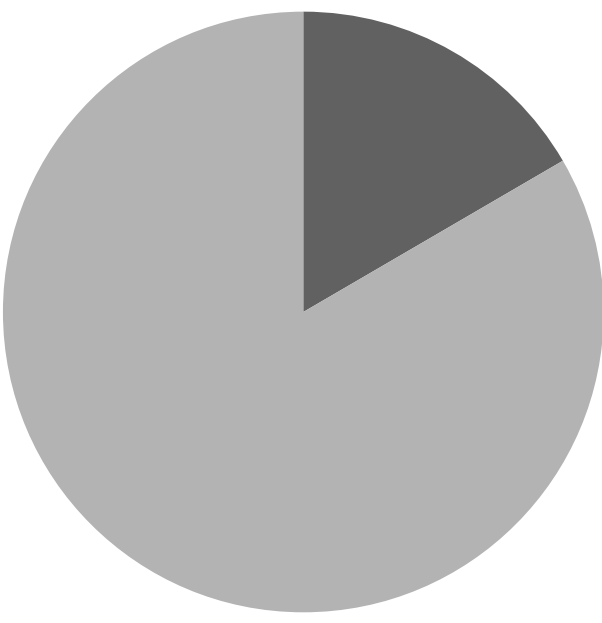

- Pro $(16,6 \%)$

Against $(83,4 \%)$

Graphic 2 - Interviewees statement about actively participating in solutions to the stray dog issue through responsible adoption programs.

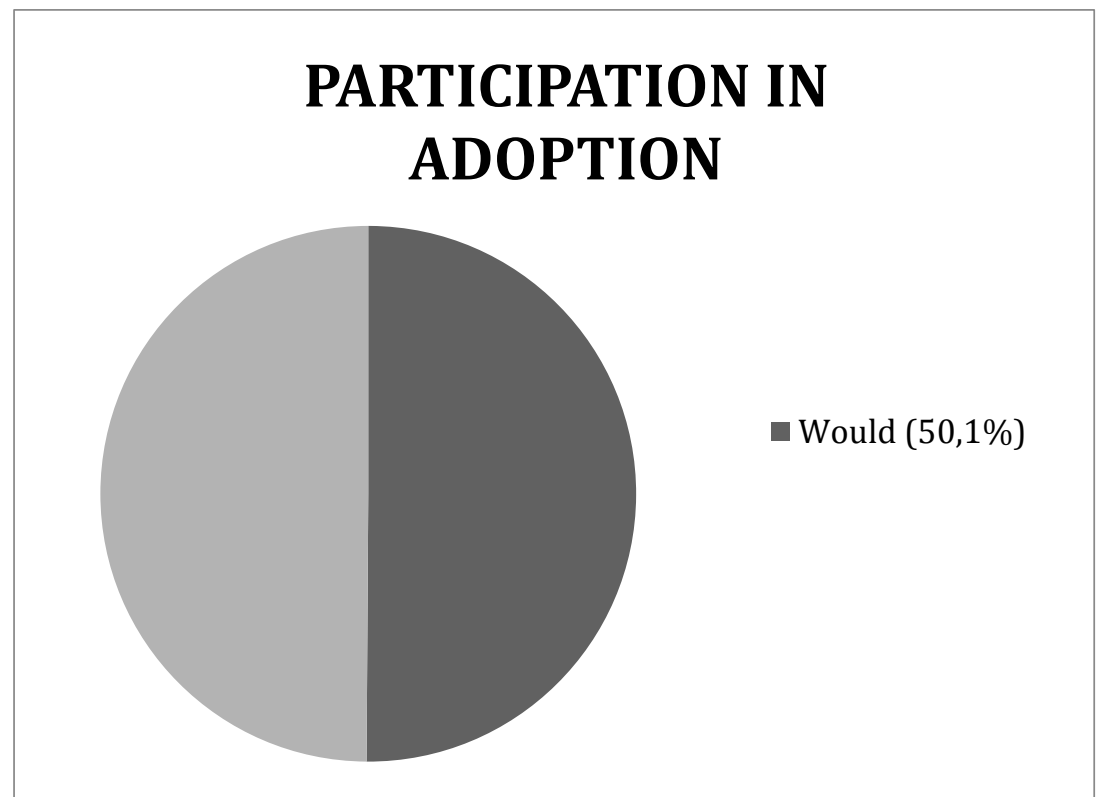

\section{DISCUSSION}

The lack of significant difference in answers between the two interview methods, except for one of the questions, gave the questionnaire a satisfactory return and standard to the two application ways. Overall, results suggest that food generated by human activity are important resources for dogs' maintenance, as well as that visitors in the campus are aware of the presence and way of life of these stray dogs. 
The ratio of interviewees complies data spread by UFV, according to which, $83 \%$ of the academic contingent is composed of students, $6 \%$ of professors and $11 \%$ of office technician servers. These percentages are close to those in the sampled category, fact that gives representativeness to the herein sampled population. There was balance between the interviewees' sex, and it avoided a gender bias in the answers. Interviewees are frequent visitors in the campus, and it may have helped the precision on observations, on the elaboration of critics and on the awareness about the ways of life of these stray dogs.

Interviewees perceived that almost all stray dogs in the campus are male and have undefined breed. Moreover, they stated that there are more males than females, and it is consistent with the stray dog profile described in other studies conducted in different parts of the world (CAMPOS et al., 2007; CLEAVELAND, 1996; DANIELS; BEKOFF, 1989a; RATSITORAHINA et al., 2009; TOTTON et al., 2010).

A considerable fraction of interviewees stated to daily see up to $50 \mathrm{dogs} / \mathrm{km}^{2}$. A study conducted at Luiz de Queiroz Campus - São Paulo University (USP-ESALQ) evidenced that the density of animals on sight, either in winter or in summer, was $76.8 \mathrm{dogs} / \mathrm{km}^{2}$ (CAMPOS et al., 2007), fact that causes much trouble to society and to the environment. Demographic data generated in the present study suggest a population of lower density.

A factor responsible for gathering many dogs in a certain location is the estrous cycle of bitches (GHOSH; CHOUDHURI; PAL, 1984). It is common seeing females in heat in the campus, and most of the interviewees stated that these females were surrounded by many males. During such events, males surround, chase and show more aggressiveness around the females. The attempts to, or actual mating, are common. According to the interviewees, behaviors changed in the pack when there was a female in heat.

Interviewees stated rarely seeing females with puppies in the campus. Such rare scene results from two main factors according to data in the literature. First, females use to hide the litter in protected nests, fact that makes it difficult seeing the puppies (DANIELS; BEKOFF, 1989a). There are forest fragments in UFV, and it impairs the possible visualization of these dens or shelters. The other important factor is the high mortality of stray dog puppies (between 70\% and 90\%), which is highlighted in many studies (BOITANI; CIUCCI, 1995; DANIELS; BEKOFF, 1989b; MACDONALD; CARR, 1995; NESBITT, 1975; SCOTT; CAUSEY, 1973).

According to GHOSH; CHOUDHURI; PAL (1984), there is negative correlation between the number of males and successful mating; when there are three to six males around a receptive female, mating is successful in only $5 \%$ of the cases. Thus, the estimate of males seen in the campus around a bitch in heat suggests low mating success. Feral dogs in rural areas in Italy also present low reproduction success (BOITANI et al., 1995). The low sight of bitches with puppies also lies on the difficulty of achieving successful mating under the conditions lived by the herein assessed stray dogs. However, dog sterilization programs are valid, since the low concentration of females with puppies in the campus suggests that most of the stray dogs living there were abandoned; one of the possible reasons for that is the undesired pregnancy or the inconvenient of puppies without post-weaning destination.

The campus seems to be the dogs' territory in the current study, since they are rarely seen on the adjacent streets or in other neighborhoods. Territoriality is not an obstacle to segregate dogs within more restricted and aggressively defended spaces (DANIELS; BEKOFF, 1989b). Dogs are more often seen in cafeterias and snack shops within this region, where there are abundant food sources. Dogs seem to be attracted to these areas due to the availability of discarded food, or food deliberately provided by people, which is a well-known association between territory occupation and food resource availability (BRADSHAW, 2006).

Although dogs are not fed by most of the interviewees, these animals are often fed by some other people (personal observation). Therefore, food resource of human origin, either provided by people or by garbage exploration, is a resource of added value to stray dogs in the campus. Actually, there are studies showing that there are more stray dogs where food availability is higher; as well as there is positive correlation between the number of individuals and garbage excess (BECK, 1973).

Food provided, or the consumption of human byproducts (Garbage), are predictable food sources and cheaper to get. Different from feral dogs, stray dogs depend on human activity and are friendly related to humans if there are opportunities to (DANIELS; BEKOFF, 1989b). Accordingly, interviewees reported that dogs digging garbage do not keep a totally functional repertoire of haunting behaviors.

The UFV campus area has approximately 305 ha of forest fragments with Atlantic Forest wood remnants. These forest remnants can hold many wild animals or synanthropic species living, or transiting, through fragments of this space. This diverse fauna could work as food, or competition source, for these stray dogs, but interviewees mentioned to rarely see dogs chasing or eating decaying animals. Therefore, according to the community, stray dogs in the campus do not seem to be a threat to the local fauna, fact that minimizes the impacts these dogs could have on wild populations (CAMPOS et 
al., 2007). This result goes against the perception of rural dog tutors described in a recent study conducted in Viçosa County, who reported that their dogs have free access to, and transit in, preserved areas where they regularly hunt wild animals (MARTINEZ et al., 2013).

There is also the concern of society about the well-being of these dogs, fact that reinforces the habit, or tolerance, of providing them food. Such informal care, or the availability of food sources generated by leftovers and garbage cans may inhibit the search for wild bates in the local fauna by dogs. Forest remnants surround the central region and, because they are isolated and quite wooded, they live with low human flow. Although it was not addressed in the questionnaire, the transit of most university users in the forest region seem to be rare. The access to these areas is difficult due to many natural (dense woods, steep terrain slope) and artificial barriers, such as fences.

The study by Campos et al. (2007), which was conducted at USP-ESALQ, evidenced that dogs have opportunistic behavior and have a diet based on a large variety of wild animals, and it contrasts the low predation shown by the stray dogs in the campus of UFV. Such contrast between stray dogs in the two academic centers suggest that food availability is enough to the estimate dog density in UFV, and it stops them from exercising their hunting behavior to fulfill their eating needs.

The abandonment of domestic animals close to veterinary hospitals in Brazilian universities is common (DILLY et al., 2005; CAMPOS et al., 2007). Some people decide to get a dog as pet without having proper guidelines and sense of responsibility; therefore, they end up abandoning the pet because it is not convenient, or because it no longer fulfills the tutors' needs (FRANK, 2004). Such acts evidence the lack of responsible ownership associated with noncompliance with the law protecting animals against bad treatment. The low record of abandonment in the campus because of the illegality of this act, and the legal consequences of it, forces those who do so to hide their action.

The overpopulation of stray dogs in places where there are no programs and activities to combat and control such burden leads to higher risk of zoonoses (MATTER; DANIELS, 2000). Many countries adopt sanitation measures in order to minimize the stray dog issue (SRINAVASAM, 2012), although, as it seems, their effectiveness is questionable (WHO, 1990). It leads to hard critics raised by different groups in society, for example, organizations to protect animals and religious groups that condemn euthanasia and/or sterilization as ways to control population growth.

Most campus users are aware of the presence of stray dogs and of the possible troubles caused by lack of control. Interviewees realized that it is a problem to the dogs themselves and to other people, but the questionnaire did not allow continuing with these arguments in order to better understand these phenomena. These data comply the study conducted in Alegre, ES, in which most of the population (83\%) highlights that "stray dogs" are a problem in the city (LOSS et al., 2012). The authors of this study suggested that aggression against dogs is the factor mostly sensitizing people in the city, although they observed that tutors do not care about the feces left on the streets by their own animals (LOSS et al., 2012).

There is a moral dilemma about the destiny given to stray dogs. Most Brazilian counties have euthanasia as the practice adopted when dogs are not adopted or rescued by other tutors. Dog euthanasia has been strongly criticized and little accepted in many parts of the world (for example, in Taiwan, HSU; SERPELL, 2003; and in India SRINAVASAM, 2012). The present study evidenced that the population in the campus is also sensitive to stray dog elimination. Most of the interviewees are against euthanasia as control method (Graphic 1). Moreover, a significant fraction of interviewees is willing to help by taking part in civil responsibility programs. It seems that by getting aware of the problem, they want to find a solution by accepting to co-participate in adoption campaigns (Graphic 2). Another fraction of interviewees, however, seem to want a solution, but do not want to co-participate.

The adoption campaign strategy can use this fraction of the population with the potential to adopt and to get responsible for stray dogs. The objection for euthanasia, however, can be explored so that other strategies are put in place in order to avoid confrontation between "policymakers" and the community in the campus.

\section{CONCLUSION}

The present investigation provides important information concerning people's perception about stray dogs' food-resource use and life style in the central campus of UFV. The dogs live inside the college campus and because they interact with the community they are tolerated and allowed to explore the garbage and to be fed by other people. It looks like the different feeding points and the abundant availability of food decrease the predatory pressure of dogs over the wild fauna. The origin of stray dogs is unknown, since there are only few records of abandonment and procreation inside the campus. Dogs are not ignored by the community, and half of the people could potentially get involved in a more acceptable solution than apprehension and euthanasia.

\section{ACKNOWLEDGEMENT}

We are grateful for the comments and technical contributions from Medeiros, T. M. M. The current research was supported by Capes e FAPEMIG . 


\section{REFERENCES}

BECK, A. M. 1973. The ecology of stray dogs: a study of free-ranging urban animals. York Press, Baltimore. 98.

BOITANI, L; CIUCCI, P. 1995. Comparative social ecology of feral dogs and wolves. Ethology Ecology \& Evolution. 7(1): 49-72.

BOITANI, L. et al. 1995. Population biology and ecology of feral dogs in central Italy. In: Serpell J. A. The domestic dog: its evolution, behaviour and interactions with people. Cambridge University Press. Cambridge, United Kingdom. 217-244.

BRADSHAW, J. W. S. 2006. The evolutionary basis for the feeding behavior of domestic dogs (Canis familiaris) and cats (Felis catus). Journal of Nutrition. 136(7): 1927S-1931S.

BRASIL 2011. Ministério da Saúde. Secretaria de Vigilância em Saúde. Departamento de Vigilância Epidemiológica. Normas técnicas de profilaxia da raiva humana / Ministério da Saúde, Secretaria de Vigilância em Saúde, Departamento de Vigilância Epidemiológica. Brasília : Ministério da Saúde, 2011. 60 p. : il. - (Série A. Normas e Manuais Técnicos) ISBN 978-85-334-1785-4.

CAMPOS, C. et al. 2007. Diet of free-ranging cats and dogs in a suburban and rural environment, south-eastern Brazil. Journal of Zoology. 273(1): 14-20.

ClEAVEland, S. 1996. The Epidemiology of Rabies and Canine Distemper in the Serengeti, Tanzania. University of London, London.

DANIELS, T. J; BEKOFF, M. 1989a. Population and social biology of free ranging dogs, Canis familiaris. Journal of Mammalogy. 70(4): 754-762.

DANIELS, T. J; BEKOFF, M. 1989b. Spatial and temporal resource use by feral and abandoned dogs. Ethology. 81(4): 300-312.

DASZAK, P.; CUNNINGHAM, A. A.; HYATT, A. D. 2000. Emerging infectious diseases of wildlife - threats to biodiversity and human health. Science, 287(5452): 443-449.

DILLY, B. L. G. et al. 2005. Tratamento dado ao problema de abandono de cães na Unicamp. Revista Ciências do Ambiente On-Line. 1(1): 5662.

EISENLOHR, P. V. et al. 2008. Flora fanerogâmica do campus da Universidade Federal de Viçosa, Viçosa, Minas Gerais. Revista Ceres. 55(4): 317-326.

FRANK, J. 2004. An Interactive Model of human and companion animal dynamics: the ecology and economics of dog overpopulation and the human costs of addressing the problem. Human Ecology. 32(1): 107130.

FRIGERI, E.; CASSANO, C. R.; PARDINI, R. 2014. Domestic dog invasion in an agroforestry mosaic in southern Bahia, Brazil. Tropical Conservation Science 7(3): 508-528.

GHOSH, B., CHOUDHURI, D. K., Pal, B. 1984. Some aspects of the sexual behaviour of stray dogs Canis familiaris. Applied Animal Behaviour Science. 13(1-2): 113-127.

HSU, Y \& SERPELL, J. A. 2003. Development and validation of a questionnaire for measuring behavior and temperament traits in pet dogs. Journal of the American Veterinary Medical Association. 223(9): 1293-1300.

IBGE - Instituto Brasileiro de Geografia e Estatística. Dados do Censo Demográfico de 2010 . Disponível em <http://www.ibge.gov.br/cidadesat/link.php?codmun=317130>. (acesso em março de 2012).

LENTH, B. E.; KNIGHT, R. L.; BRENNAN, M. E. 2008. The effects of dogs on wildlife communities. Natural Areas Journal. 28(3): 218-227.
LOSS, L. D. et al. 2012. Posse responsável e conduta de proprietários de cães no município de Alegre-ES. Acta Veterinaria Brasilica, 6(2): 105111.

MACDONALD, D. W; CARR, G. M. 1995. Variation in dog society: between resource dispersion and social flux. In: Serpell J. A. The domestic dog: its evolution, behaviour and interactions with people. Cambridge University Press. Cambridge, United Kingdom. 199216

MARTINEZ, E. et al. 2013. Domestic dogs in rural area of fragmented Atlantic Forest: potential threats to wild animals. Ciência Rural, 43(11): 1998-2003.

MATTER, H. C.; DANIELS, T. J. 2000. Dog ecology and population biology. In: Macpherson, C. N. L., Meslin, F.X., Wandeler, A. I. Dogs, Zoonoses and Public Health. CAB International, Wallingford, Oxon. UK. 17-62.

NESBITT, W. H. 1975. Ecology of a feral dog pack on a wildlife refuge. In: Fox, M. W. The wild canids: their systematics, behavioral ecology end evolution. Malabar. Robert E. Krieger Publishing. 391395.

PAULA, A. et al. 2004. Sucessão ecológica da vegetação arbórea em uma Floresta Estacional semidecidual, Viçosa, MG, Brasil. Acta Botanica Brasilica. 18(3): 407-423.

PEREIRA, R. A. et al. 2001. Caracterização da paisagem, com ênfase em fragmentos florestais, do município de Viçosa. Revista Árvore. 25(3): 327-333.

RATSITORAHINA, M. et al. 2009. Dog ecology and demography in Antananarivo, 2007. BMC Veterinary Research. 5(1): 1-7.

SCOTT, M. D; CAUSEY, K. 1973. Ecology of feral dogs in Alabama. Journal of Wildlife Management. 37: 253-265.

SERPELL J. A. 1995. The domestic dog: its evolution behaviour and interactions with people. Cambridge University Press, Cambridge. 268.

TAN, J. S. 1997. Human zoonotic infections transmitted by dogs and cats. Archives of Internal Medicine, 157(17): 1933-1943.

TOTTON, S. C. et al. 2010. Stray dog population demographics in Jodhpur, India following a population control/rabies vaccination program. Preventive Veterinary Medicine. 97(1): 51-57.

VOSLÁRVÁ, E; PASSANTINO, A. 2012. Stray dog and cat laws and enforcement in Czech Republic and in Italy. Annali dell'Istituto Superiore di Sanità. 48(1): 97-104.

WHO. 1990. World Health Organization. Guidelines for dog population management. Geneva. 116. 